\title{
Allelopathic effect of Ailanthus altissima on wheat (Triticum aestivum $\mathbf{L}$.)
}

\author{
Zakir Ullah ${ }^{1}$, Syed Inzimam Ul Haq ${ }^{2 *}$, Shah Khalid ${ }^{2}$, Khalid Kamran ${ }^{3}$, \\ Amir Khan ${ }^{2}$ and Sheraz Ahmad ${ }^{4}$ \\ 1. Department of Botany, Abdul Wali Khan University, Mardan, KPK-Pakistan \\ 2. Department of Botany, Islamia College Peshawar, KPK-Pakistan \\ 3. Department of Botany, PMAS-Arid Agriculture University, Rawalpindi-Pakistan \\ 4. Department of Chemical and Life Sciences, Qurtuba University of Science \& Information Technology, Peshawar, \\ KPK-Pakistan \\ *Corresponding author's email:syedinzimam74@gmail.com
}

Citation

Zakir Ullah, Syed Inzimam Ul Haq, Shah Khalid, Khalid Kamran, Amir Khan and Sheraz Ahmad. Allelopathic effect of Ailanthus altissima on wheat (Triticum aestivum L.). Pure and Applied Biology. Vol. 9, Issue 1, pp309319. http://dx.doi.org/10.19045/bspab.2020.90036

\begin{tabular}{llll}
\hline \hline Received: 02/05/2019 & Revised: 15/09/2019 & Accepted: 24/10/2019 & Online First: 06/11/2019 \\
\hline \hline
\end{tabular}

\section{Abstract}

The allelopathic potential of Ailanthus altissima L. was investigated against Triticum aestivum L. variety Atta habib in the laboratory. Dry and fresh plant materials of Ailanthus altissima at $5 \mathrm{~g}, 10 \mathrm{~g}$ and $15 \mathrm{~g}$ weight were soaked in $100 \mathrm{ml}$ distilled water. The materials were filtered after $24 \mathrm{hrs}\left(1^{\text {st }}\right.$ treatment), $48 \mathrm{hrs}\left(2^{\text {nd }}\right.$ treatment $)$ and $72 \mathrm{hrs}$ ( $3^{\text {rd }}$ treatment $)$. The extracts were applied to wheat grain to investigate their impact on radicle length, germination percentage and plumule length after 72 hours of incubation at $26^{\circ} \mathrm{C}$. The result revealed that the extrect of fresh and dried leaves of Ailanthus altissima L. had inhibitory effect on germination percentage, plumule length and radicle length of Triticum aestivum. As compared to germinaton percentage, radicle and plumule length was more affected. The inhibitory effect of dried leaves on the test plant was more pronounced than the fresh leaves. The most inhibitory treatment which effect radicle length was $15 \mathrm{~g}$ dry leaves extract in 48 hours sokaing duartion, which reduced the radicle length up to $0.67 \mathrm{~mm}$, as compared to control $(18.2 \mathrm{~mm})$. The most inhibitory treatment which effect plumule length was $10 \mathrm{~g}$ dry leaves extract in 48 hours soaking duration, which reduced the plumule length up to $0.26 \mathrm{~mm}$ as compared to control $(7.8 \mathrm{~mm})$. Germination percentage was also induced by $10 \mathrm{~g}$ dry leaves extract in 48 hours soaking duration which reduced germination percentage to $13.33 \%$ as compared to control (100\%). The reported inhibitory effects suggests the presence of some kinds of allelochemicals in Ailanthus altissima L. inhibited the germination and growth of the wheat.

Keywords: Ailanthus altissima L.; Allelopathy; Germination percentage; Inhibitory effect; Plumule length; Radicle length; Triticum aestivum L.

\section{Introduction}

Ailanthus altissima L. is a medium sized tree which extend to a height between 17 and 27 meters (56 and $89 \mathrm{ft}$ ). The diameter is about 1 meter (39 inches) at breast height [1]. Triticum aestivum L. belongs to Poaceae family. It is cereal grain and is cultivated worldwide. Wheat is the most produced crop in the world after maize and rice. The production of wheat is estimated to about 691 million tons per year. As compared to other crops, it is grown on more area and is 
considered the most important food crop in the world. The trade of wheat is more than any other crop plant [2]. In 1937 an Austrian scientist, Molisch coined the term allelopathy which is a compound of two Greek words, allelon which means 'mutual' and pathos means to suffer. Allelochemicals may be defined as the beneficial or harmful effects of one plant on another plant through the release of biochemicals. Those allelochemicals which are having negative effects plays an important role in the defence of plant against herbivory [3, 4]. Allelopathy involves the ecological communications between species [5]. Secondary metabolites of the plants that are responsible for the allelopathic potential of the plants are known as allelochemicals. De Candolle [6] was the first person which proposed that there is a possibility that many plants may extract something from their roots which may be injurious to other plants. Allelochemicals are a subset of secondary metabolites not required for growth and development of the allelopathic organism. Anjum [7] studied the allelopathic effect by using sandwich method of some selected medicinal plants on lettuce seeds. He selected fourteen medicinal plants of semi-arid plain areas and performed experiment in the laboratory using sandwich method to evaluate their allelopathic action. The inhibitory (toxic) and stimulatory (nontoxic) effects were evaluated and studied their effect on germination, radicle length, growth percentage of hypocotyls. Both effects were examined for hypocotyl growth of lettuce seeds under the influence of leaves. Though the inhibitory and stimulatory effect of leaves varied with the plant species. From the results it was concluded that Broussonetia papvrifera and Albizia lebbeck possessed strong inhibitory effect on lettuce radicle length and growth of hypocotyls. Nakafeero [8] evaluated the allelopathic potential for five multipurpose trees that are currently promoted for agro-forestry in Botswana:
Acacia tortilis, A. erubescens and Terminalia sericea and it was established that leaves from each species contained a variety of phenolic compounds (flavonols, flavonones, anthocynins, coumarins, leucoanthocynins, tannins) and alkaloids (tertiary and quaternary alkaloids) in varying concentration which are having allelopathic activity against plants in their vicinity. Gomez-Aparicio [9] studied the allelopathic effects of invasive tree Ailanthus altissima on three native tree species; Acer rubrum, Acer Saccharum and Quercus rubra and observed their emergence of seedling, survival and growth. From the results it was evaluated that the allelopathic effects of Ailanthus altissima were proportional to the density of neighborhood Ailanthus, regardless of their size. In difference, the effects of Ailanthus were strongly influenced by distance from a tree, mostly dropping to zero within $5 \mathrm{~m}$ from the trunk. Youngling [10] studied that wheat (Triticum aestivum L.) has allelopathic potential if used as a cover crop for weed control in various cropping system. Many researches showed that, among modern verities, there is a variable resistance potential against weeds. A large number of allelopathic compound have been identified in wheat, mainly belonging to the categories of phenolic acids, hydroxamic acid and short chain fatty acids. The negative effects of other crops under different agriculture production systems have been reported. Lin [11] studied the allelopathic effect of aqueous extract of Aloe vera leaf on initial seedling and germination of four crops; radish, lettuce, turnip and rice and re-rooting ability in sweet potato and rice. It was concluded that the germination showed no effect with the extract, but the root length and height of seedling was significantly promoted in all test crops. The number of roots was increased in turnip and lettuce. Beyond this the extract possessed stimulatory effects on re-rooting ability in sweet potato and rice seedling. 
From the results it was suggested that the aqueous extract of Aloe vera leaf could be used as a natural regulator in plant growth, as it promotes initial growth of seedling and cutting in roots.

Materials and methods

Collection, drying, crushing and storage of plant material

Ailanthus altissima leaves were collected in February 2016. Some of plant leaves were separated and was dried in shade. The dried material was slightly crushed and stored in polythene bags for use in future. Fresh material was washed after collection and was chopped straight away for extract.

\section{Relative toxicity of plant part}

Aqueous extracts were prepared by soaking each $5 \mathrm{~g}, 10 \mathrm{~g}$ and $15 \mathrm{~g}$ (dried and fresh separately) leaves in $100 \mathrm{ml}$ of distilled water for 24,48 , and 72 hours at room temperature. It was filtered, and the extracts were used as stock solution for future use. Distilled water was used against Triticum aestivum L. as control treatment. The apparatus used in the research was Beaker, Filter paper, Petri dishes, Titration flasks, Incubator, Refrigerator and Mortar and pestle. Petri dishes were lined with doubly folded Whatman No.1 filter paper. Each Petri dish was provided with 5 healthy grains of wheat that were placed at equal distance on the filter paper. Before using the wheat, seeds were put in water to check the viability i.e., the seeds that settled down in water are viable seeds. The seed bed i.e., filter paper was moistened with $3 \mathrm{ml}$ of plant extract or distilled water in case of control. These Petri dishes containing wheat grains were placed in incubator at $26^{\mathrm{O}} \mathrm{C}$ for 72 hours. Each treatment had 3 replicates. After 48 hours incubation period, the parameters were measured such as;
Radicle length, Plumule length and Germination Percentage.

Results

Effect of 24 hours soaking duration extract on radicle length

The result showed that inhibitory effect of Ailanthus altissima were concentration dependent. As the concentration of fresh and dried leaves increased, reduction in the radicle length was more. It can be seen from figure 1 that dry leaves were more inhibitory than fresh leaves. Most inhibitory treatment was $10 \mathrm{~g}$ of dried leaves which reduced the radicle length to $1.33 \mathrm{~mm}$ as compared to control $(18.2 \mathrm{~mm})$. Second most inhibitory treatment was $15 \mathrm{~g}$ of both fresh and dried leaves, reducing the parameter to 5.6 and 5.8 $\mathrm{mm}$ respectively, followed by $10 \mathrm{~g}$ fresh $(6.67 \mathrm{~mm})$ and $5 \mathrm{~g}$ dry leaves extract $(6.2 \mathrm{~mm})$ as compared to control. Least inhibition in the radicle length was reported in case of $5 \mathrm{~g}$ of fresh leaves with a reduced value of 9.07 $\mathrm{mm}$ (Figure 1).

\section{Effect of 48 hours soaking duration extract on radicle length}

Figure 2 showed that all the treatment was inhibitory for radicle length. It is obvious from the figure that dry leaves extract was having more inhibitory effects on the radicle length. Most inhibition in radicle length was seen in $10 \mathrm{~g}$ and $15 \mathrm{~g}$ of dry leaves, reducing the radicle length up to $0.86 \mathrm{~mm}$ and $0.67 \mathrm{~mm}$ respectively, compared to control (18.2 $\mathrm{mm})$. Ten-gram treatment of the fresh leaves was the least inhibitory treatment $(8 \mathrm{~mm})$ followed by $5 \mathrm{~g}$ of fresh leaves $(6.87 \mathrm{~mm})$. The result showed that inhibitory effect is concentration dependent as we increase the concentration of fresh and dry material for extract the radicle length decreased in same manner (Figure 2). 


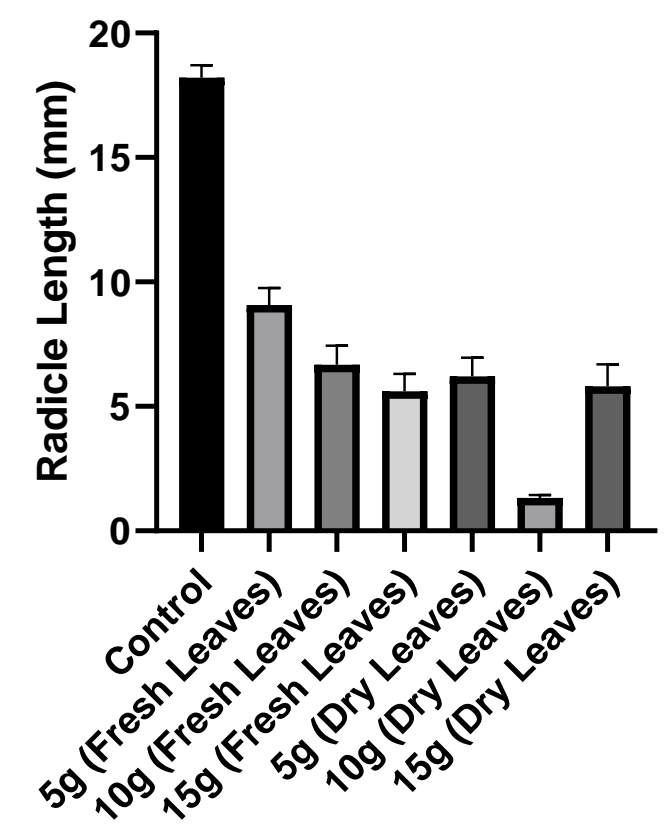

Figure 1: Effect of 24 hours soaking duration extract

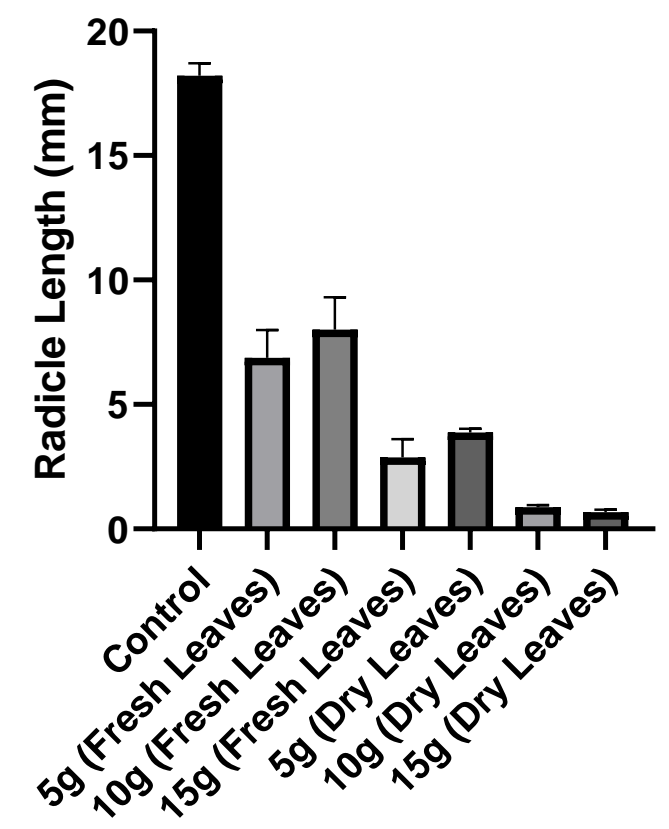

Figure 2: Effect of 48 hours soaking duration extract

Effect of 72 hours soaking duration extract on radicle length

The result showed that inhibitory effect of Ailanthus

are concentration dependent as the concentration of fresh and dried leaves increased, reduction in the radicle length was more. It can be seen from the figure 3 , that dry leaves were inhibitory 
than fresh leaves. Most inhibitory treatment was $10 \mathrm{~g}$ of dried leaves which reduced the radicle length to $2.867 \mathrm{~mm}$ as compared to control (18.2). Second most inhibitory treatment was $15 \mathrm{~g}$ and $5 \mathrm{~g}$ dried leaves extract, reducing the parameter to $3.16 \mathrm{~mm}$ and $3.94 \mathrm{~mm}$ respectively, followed by $15 \mathrm{~g}$ fresh $(4.07 \mathrm{~mm})$ and $10 \mathrm{~g}$ fresh leaves extract $(5.33 \mathrm{~mm})$ as compared to control $(18.2 \mathrm{~mm})$. Least inhibition in the radicle length was reported in case of $5 \mathrm{~g}$ of fresh leaves with a reduced value of $7.2 \mathrm{~mm}$ (Figure 3 ).

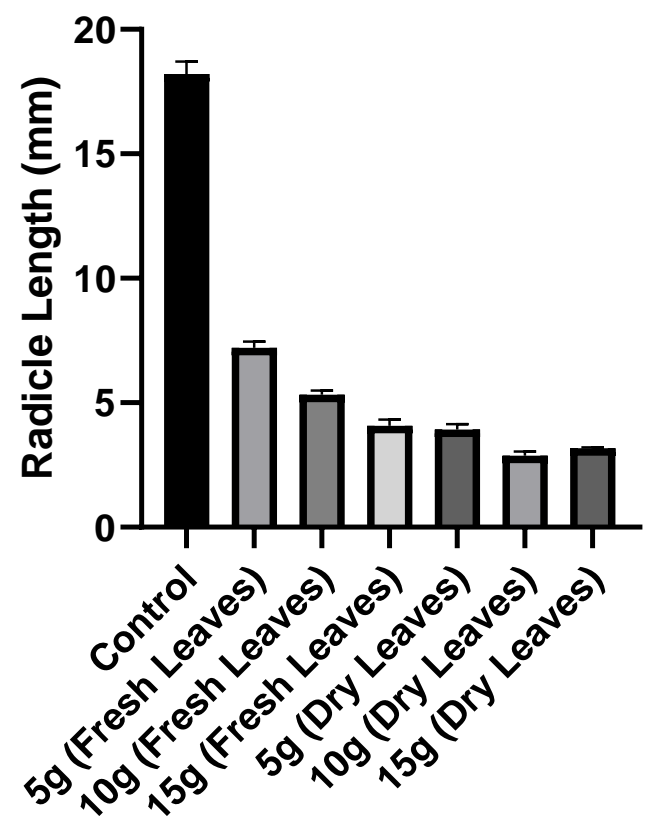

Figure 3: Effect of 72 hours soaking duration extract

Effect of 24 hours soaking duration extract on germination percentage

Extract obtained from 10 grams of dry leaves was the most reducing concentration for the germination percentage, reducing the parameter to $26.67 \%$, compared to control $(100 \%)$. Least inhibition in the germination percentage was seen in case of $10 \mathrm{~g}$ extracts of fresh leaves followed by $15 \mathrm{~g}$ of fresh leaves, which caused reduction in germination percentage up to $93.33 \%$ and $80 \%$ respectively while $5 \mathrm{~g}$ fresh leaves extract was altogether without any effect. There was a different trend observed in the dry leaves extracts as most inhibitory treatment was $10 \mathrm{~g}$ concentration $(26.67 \%)$ rather than $15 \mathrm{~g}$, which reduced the percent germination to $53.33 \%$ (Figure 4). 


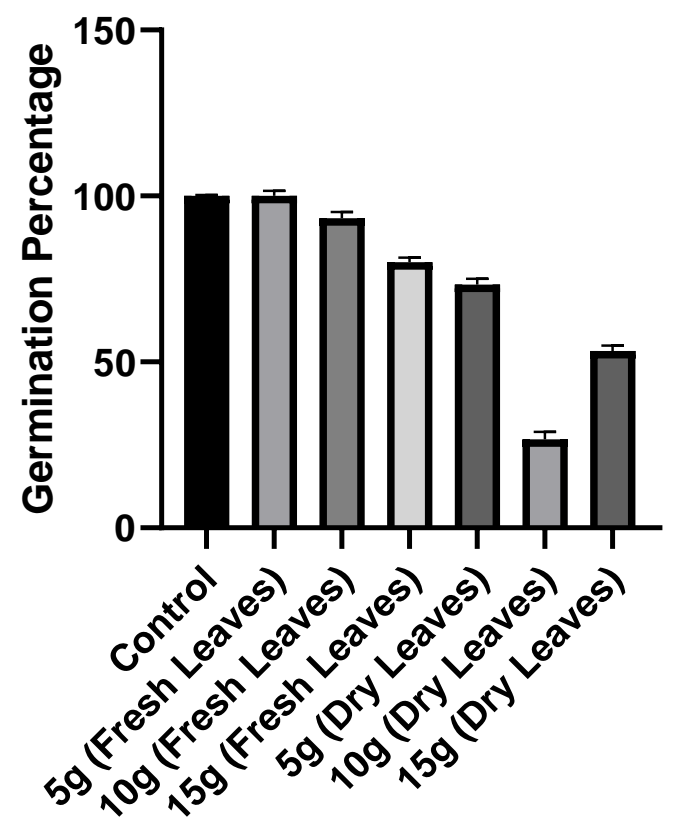

Figure 4: Effect of 24 hours soaking duration extract

Effect of 48 hours soaking duration extract on germination percentage

The data revealed that fresh leaves extracts was having very little effect on the germination of the wheat plant. In fresh leaves extract only reduction was caused by $15 \mathrm{~g}$ leaves extract, with a reduction to $80 \%$ while $5 \mathrm{~g}$ fresh leaves extract was altogether without any effect. Dry leaves extract was having a very pronounced effect on the germination percentage of wheat and the parameter was reduced to as low as $13.33 \%$ in case of $10 \mathrm{~g}$ dry leaves extract. Second most inhibitory treatment was $15 \mathrm{~g}$ of dry leaves. Effect of $5 \mathrm{~g}$ dry leaves was similar to
$15 \mathrm{~g}$ fresh leaves and reduced the germination of wheat to $80 \%$ (Figure 5).

Effect of 72 hours soaking duration extract on germination percentage.

Extract obtained from $15 \mathrm{~g}$ of dried leaves was the most reducing concentration for the germination percentage, reducing the parameter to $66.67 \%$ compared to control $(100 \%)$. Least inhibition in the germination percentage was seen in case of $10 \mathrm{~g}$ and $15 \mathrm{~g}$ extracts of fresh leaves with a reduction up to $80 \%$ each, while $5 \mathrm{~g}$ fresh leaves extract was altogether without any effect. Extract from $5 \mathrm{~g}$ and $10 \mathrm{~g}$ dried leaves were having the same reduction capability and reduced the germination to $73.33 \%$ each (Figure 6). 


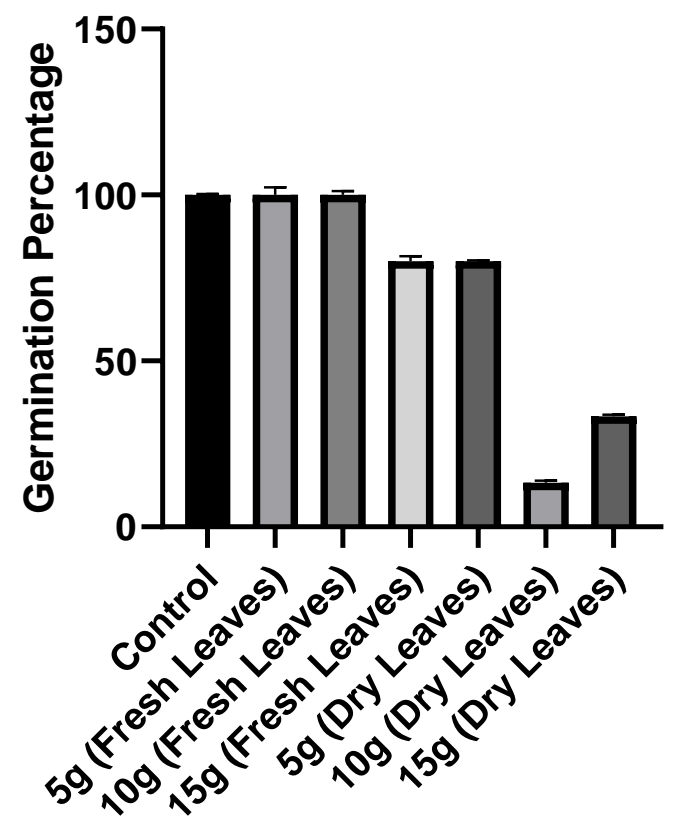

Figure 5: Effect of $\mathbf{4 8}$ hours soaking duration extract

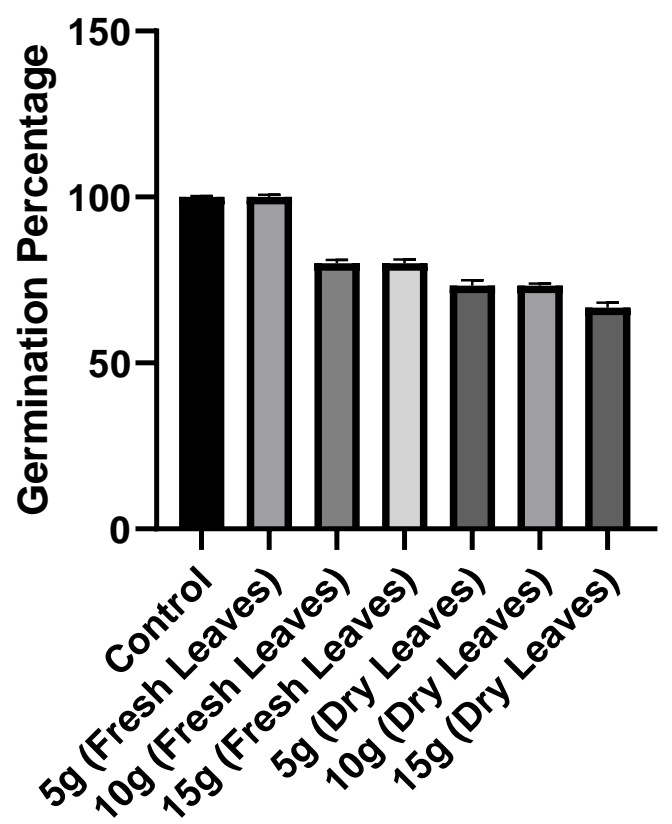

Figure 6: Effect of 72 hours soaking duration extract

Effect of 24 hours soaking duration extract on plumule length

The result showed that inhibitory effect of Ailanthus

are concentration dependent as the concentration of fresh and dried leaves increased, reduction in the plumule length was more. It can be seen from the figure 7 , that dry leaves are inhibitory 
than fresh leaves. Most inhibitory treatment was 10 gram of dried leaves which reduced the plumule length to $1.4 \mathrm{~mm}$ as compared to control (7.8). Second most inhibitory treatment was 15 and $5 \mathrm{~g}$ dried leaves extract, reducing the parameter to $1.93 \mathrm{~mm}$ and $4 \mathrm{~mm}$ respectively, followed by $10 \mathrm{~g}$ fresh $(4.73 \mathrm{~mm})$ and $15 \mathrm{~g}$ fresh leaves extract $(4.93 \mathrm{~mm})$ as compared to control $(7.8 \mathrm{~mm})$. Least inhibition in the radicle length was reported in case of $5 \mathrm{~g}$ of fresh leaves with a reduced value of $6.2 \mathrm{~mm}$ (Figure 7).

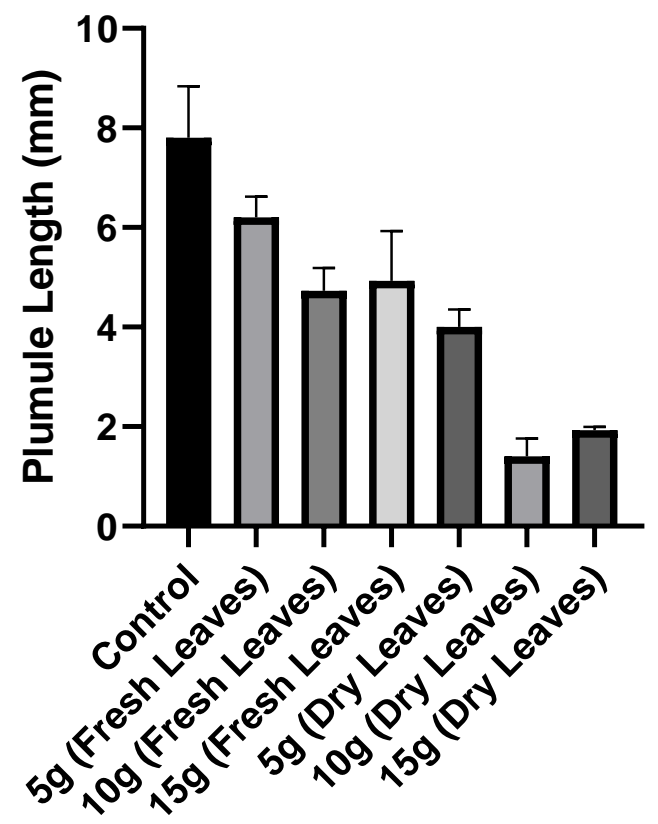

Figure 7: Effect of 24 hours soaking duration extract

\section{Effect of 48 hours soaking duration extract on plumule length}

The result showed that inhibitory effect of Ailanthus altissima are concentration dependent as the concentration of fresh and dried leaves increased, reduction in the plumule length was more pronounced. Most inhibitory treatment was $10 \mathrm{~g}$ of dried leaves which reduced the plumule length to $0.26 \mathrm{~mm}$ as compared to control (7.8). Second most inhibitory treatment was $15 \mathrm{~g}$ in case of both fresh and dried leaves, reducing the parameter to 2.4 and $0.33 \mathrm{~mm}$ respectively, followed by $5 \mathrm{~g}$ dry $(3.53 \mathrm{~mm})$ and $10 \mathrm{~g}$ fresh leaves extract $(4.53 \mathrm{~mm})$ as compared to control (7.8). Least inhibition in the radicle length was reported in case of $5 \mathrm{~g}$ of fresh leaves with a reduced value of $5.2 \mathrm{~mm}$ (Figure 8).

\section{Effect of 72 hours soaking duration extract} on plumule length

The table shows that all the treatments were inhibitory for plumule length. It is obvious from the data that dry leaves extract having more inhibitory effects on the plumule length. Most inhibition in plumule length was seen in 15 and $10 \mathrm{~g}$ of dry leaves, reducing the plumule length up to $1.86 \mathrm{~mm}$ and $2.26 \mathrm{~mm}$ respectively, compared to control $(7.8 \mathrm{~mm})$. Extracts from $15 \mathrm{~g}$ fresh and $5 \mathrm{~g}$ from dry leaves were having approximately the same inhibitory effects on the parameter with a reduction to $3.6 \mathrm{~mm}$ and $3.33 \mathrm{~mm}$ respectively. Five-gram treatment of the fresh leaves was the least inhibitory treatment 
(5.8mm) followed by $10 \mathrm{~g}$ of fresh leaves $(5.4 \mathrm{~mm})$. The result showed that inhibitory effect is concentration dependent as we increase the concentration of fresh and dry material for extract the plumule length decreased in same manner (Figure 9).

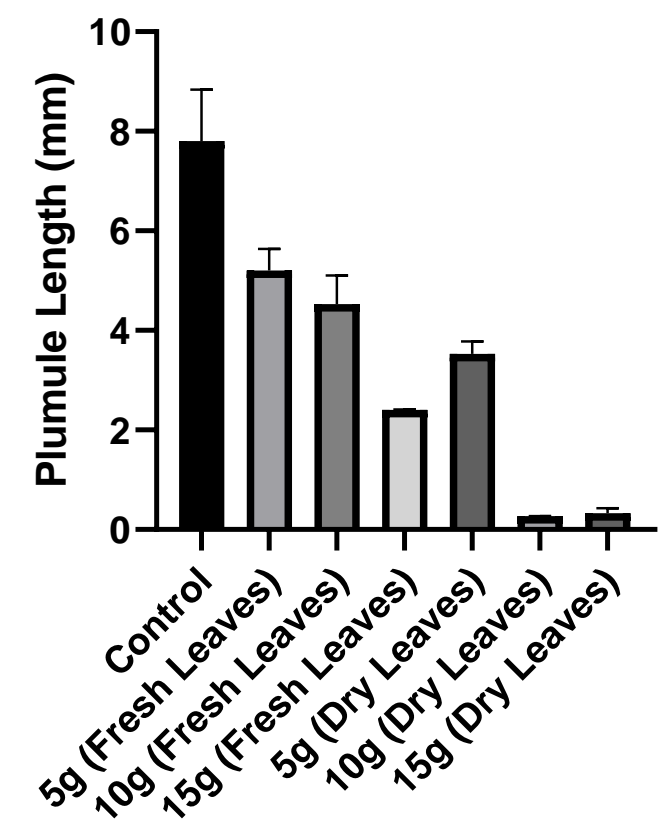

Figure 8: Effect of 48 hours soaking duration extract

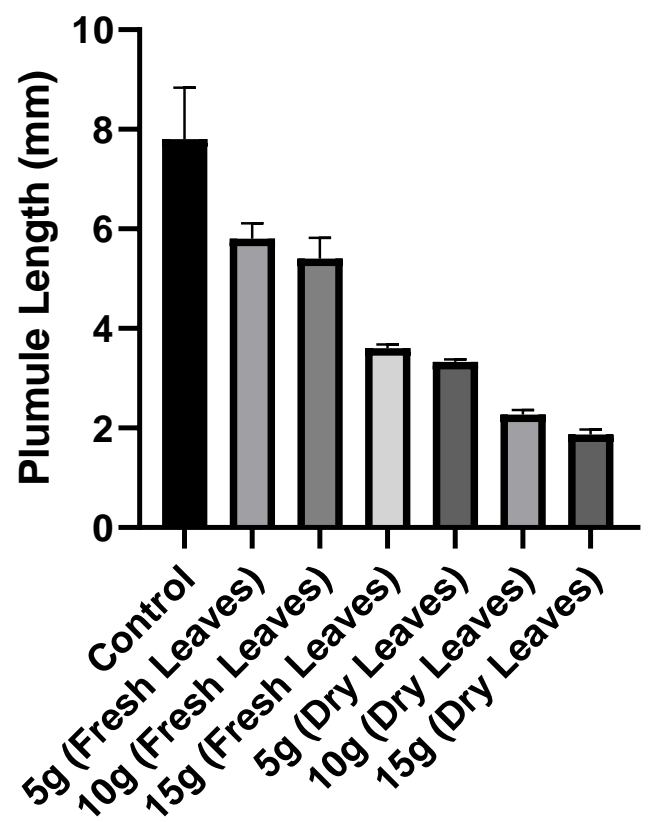

Figure 9: Effect of 72 hours soaking duration extract 


\section{Discussion}

Ailanthas altissima - the tree of heaven-is reported to have allelochemicals that have significant potential against plants. The detailed worked conducted by Heisey (1990) showed that different extracts of this plant reduced the growth and development of other plants in the vicinity [12]. The current work was carried out to look for any potential allelopathic impact of this plant on wheat germination and growth. The overall results are surprising, as almost the treatments, that were aqueous extracts, were having a potential to reduce the germination percentage and growth of the wheat. These parameters were inhibited by extracts of almost all soaking durations, which clearly indicated that the chemicals are quickly released into the environment, irrespective of the duration of soaking [13]. The radicle length was inhibited with increasing concentration and soaking time. The dry leaves extract showed more inhibition in radicle length as compared to fresh leaves extract. The increased inhibition in radicle length was recorded in $10 \mathrm{~g}$ dry leaves extract. It was also reported that fresh leaves were having less potential to reduce germination percentage, as compared to dry leaves, that may be due to the possible maturity of allelochemicals that are processed once the leaves are separated from the parent plant [14]. Another interesting phenomena was reported that out of 3 different concentration of extracts $(5 \mathrm{~g}, 10 \mathrm{~g}$ and $15 \mathrm{~g}), 10 \mathrm{~g}$ extract was most inhibitory for germination percentage and growth of the plants, that was contrary to the general idea that with increase in concentration, negative impacts increase; rather the highest concentration extract i.e. $15 \mathrm{~g}$ was stimulatory in its nature, as reported by some earlier workers. The effect of inhibition was enhanced with increasing plant material. The results showed similarity with results of Samreen [15], Ullah [16] and Hadi [17]. It's a general trend that allelochemicals may reverse its impact as per the concentration, as reported many times that increasing concentration some time cause positive effects, then negative $[18,19]$. From the results it was found that there may be some toxic allelochemicals present in plant which cause growth inhibition and development. It is recommended that these allelochemicals are required to identified and quantified for further study on allelopathy.

\section{Conclusion}

Germination was most significantly reduced by $10 \mathrm{~g}$ extract of dry leaves and as the soaking duration increased his inhibitory effects increased. The maximum inhibitory effect was observed in $10 \mathrm{~g}$ extract of dry leaves followed by $15 \mathrm{~g}$ and $5 \mathrm{~g}$. The most affected parts of Triticum aestivum were plumule followed by the radicle length. It is concluded the Ailanthus altissima leaves possess potential allelochemicals that are affecting germination percentage \& inhibiting plumule and radicle length of the Triticum aestivum.

\section{Authors' contributions}

Conceived and designed the experiments: $Z$ Ullah \& SIU Haq, Performed the experiments: Z Ullah, SIU Haq \& S Khalid, Analyzed the data: SIU Haq, S Ahmad, Z Ullah \& A Khan, Contributed materials/analysis/ tools: SIU Haq, K Kamran \& S Khalid, Wrote the paper: SIU Haq \& S Khalid.

\section{References}

1. Lawrence JG, Colwell A \& Sexton OJ (1991). The ecological impact of Allelopathy Ailanthus altissima Simaroubaceae. American $J$ of Bot 78(7): 948-958.

2. Cutris, BC (2002). Wheat in the world: Bread wheat improvement and production. Food and agric. Organization U. N., Rome, pp 1-17.

3. Fraenkel GS (1959). The Raison d'Etre of Secondary Plant Substances. Sci 129: 1466-1470. 
4. Stamp N (2003). Out of the Quagmire of Plant Defense Hypotheses. The Quarterly Rev of Biol 78: 23-55.

5. Coder KD (1999). Allelopathy in trees. University of Georgia. Daniel B Warnell School of Forest Resources Extension Publication FOR99-004.

6. de Candolle AP (1832). Plant Phisiol 3.

7. Anjum A, Hussain U, Yousaf Z, Khan F $\&$ Umer A (2010). Evaluation of allelopathic action of some selected medicinal plant on lettuce seeds by using sandwich method. J of Med Plants Res 4(7):536-541.

8. Nakafeero AL, Reed MS \& Moleele NM (2007). Allelopathic potential of five agroforestry trees, Botswana. African J of Ecol 45(4): 590-593.

9. Gomez-Aparicio L \& Canham CD (2008). Neighborhood analysis of allelopathic effects of the invasive tree Ailanthus alatissima in temperate forests. J of Ecol 96: 447-458.

10. Youngling MA (2005). Weed Management and biology. Journal Compilation 2010. Weed Sci Soc of Japan 5(3): 93-104.

11. Lin DZ, Suzuki ET, Sugimoto Y, Dong YJ, Mstsuo M \& Terao H (2004). Allelopathic effects of aqueous Aloe vera leaf extract on selected crops. Allelopathy J 13(1): 67-74.

12. Heisey RM (1990). Evidence for allelopathy by tree-of-heaven (Ailanthus altissima). J of Chem Ecol 16(6): 20392055.

13. Cheng F \& Cheng Z (2015). Research Progress on the use of Plant Allelopathy in Agriculture and the Physiological and Ecological Mechanisms of Allelopathy. Frontiers in Plant Sci 6: 1020-1020.

14. Belel MD \& Belel RD (2015). Allelopathic effect of leaf and seed extract of nutgrass (Cyperus tuberosus) on the germination of beans (Vigna unguiculata (L.) Walp). Cogent Food \& Agric 1(1).

15. Samreen $U$, Hussain $F$ \& Sher $Z$ (2009). Allelopathic potential of Calotropis procera (AIT.).L. Pak J of Plant Sci 15(1): 7-14.

16. Ullah B., Hussain F \& Ibrar M (2010). Allelopathic potential of Dodonaea viscosa (L.) jacq. Pak J of Bot 42(4): 2383-2390.

17. Hadi F, Ali G \& Rashid A (2013). Allelopathic potential of Desmostachya bipinnata (L.) P. Beauv. on wheat varieties (Ghaznavi and Tatara). Scholarly J of Agric Sci 3(8): 313-316.

18. Anwar S (2017). Effect of aqueous extracts of allelopathic plants on growth and biomass of wheat and weeds. Pure and ApplBiol 6(4): 1161-1170.

19. Kohli RK., Batish D \& Singh HP (1997). Allelopathy and Its Implications in Agroecosystems. J of Crop Prod 1(1): 169-202. 